\title{
HUBUNGAN DUKUNGAN KELUARGA DENGAN KEPATUHAN MENJALANI DIET PADA PASIEN DIABETES MELITUS DI WILAYAH KERJA PUSKESMAS BINJAI ESTATE
}

\author{
Leli Herawati \\ Program Studi Diploma III Keperawatan, STIKes Sehat Medan \\ Email: leli.herawati0987@gmail.com
}

\begin{abstract}
ABSTRAK
Diabetes melitus (DM) adalah gangguan metabolisme kronis yang ditandai dengan defisiensi produksi dan pemanfaatan hormon insulin pankreas. Keluarga memiliki pengaruh terhadap sikap dan penerimaan pendidikan kesehatan pada pasien Diabetes Mellitus. Tujuan dari penelitian ini adalah untuk mengetahui hubungan dukungan keluarga dengan kepatuhan diet pada penderita diabetes mellitus di wilayah kerja Puskesmas Binjai Estate tahun 2020. Jenis penelitian ini adalah kuantiatif non eksperimen dengan desain korelasi yang dilakukan di Wilayah Kerja Puskesmas Binjai Estate Januari - Juli 2020. Populasi dalam penelitian ini adalah seluruh penderita diabetes melitus di wilayah kerja Puskesmas Binjai Estate yang berjumlah 125 orang. Sampel dalam penelitian ini adalah penderita diabetes melitus yang berdomisili di wilayah kerja Puskesmas Binjai Estate dan yang bersedia jika peneliti menanyakan datanya sebanyak 25 responden. Hasil penelitian adalah 13 responden (52\%) memiliki dukungan keluarga yang baik dengan 12 responden (48\%) patuh menjalankan diet diabetes mellitus 1 responden, (4\%) memiliki kepatuhan diet diabetes mellitus dengan disabilitas, responden yang mendapat dukungan 9 responden (36\%) memiliki kepatuhan keluarga cukup dengan 4 responden (16\%) menjalankan diet, sedangkan 5 responden (20\%) memiliki kepatuhan diet patuh (20\%), dan 3 responden memiliki dukungan keluarga kurang (12\%), yang memiliki kepatuhan diet dan tidak patuh sebanyak 3 responden (12\%). Berdasarkan hasil uji chi-square terdapat hubungan antara dukungan keluarga dengan kepatuhan diet pada pasien diabetes mellitus dengan hasil $(p=0,003$ atau $<0,05)$. Diharapkan keluarga memberikan dukungan berupa motivasi, dukungan dan bimbingan berupa moril maupun materil agar pasien lebih mampu mengikuti diet diabetes mellitus dalam menjaga kadar gula darah.
\end{abstract}

Kata Kunci: Dukungan Keluarga, Kepatuhan Diet, Diabetes Mellitus.

\section{ABSTRACT}

Diabetes mellitus (DM) is a chronic metabolic disorder characterized by a deficiency in the production and utilization of the pancreatic hormone insulin. Families have an influence on attitudes and acceptance of health education in Diabetes Mellitus patients. Because this disease has a big challenge to achieve success in its management, because it must be done for life so that boredom and non-compliance often occur. Family support is needed to improve dietary compliance in DM patients. The purpose of this study was to determine the relationship between family support and dietary compliance in people with diabetes mellitus in the Binjai Estate Health Center Working Area in 2020. This type of research was a nonexperimental quantitative with a correlation design conducted in the Binjai Estate Health Center Work Area January - July 2020. The population in this study were all people with diabetes mellitus in the working area of the Binjai Estate Health Center, amounting to 125 people. The sample in this study were people with diabetes mellitus who lived in the working area of the Binjai Estate Health Center and who were willing if the researcher asked for data as many as 25 respondents. The results of the study were 13 respondents (52\%) had good family support with 12 respondents (48\%) obedient to the diabetes mellitus diet, 1 respondent (4\%) had diabetes mellitus diet compliance with disability, respondents who received support from 9 respondents (36\%) ) had sufficient family compliance with 4 respondents (16\%) following a diet, while 5 respondents (20\%) had a compliant diet (20\%), and 3 respondents had less family support (12\%). obedient as many as 3 respondents (12\%). Based on the results of the chi-squer test, there is a relationship between family support and dietary compliance in patients with diabetes mellitus with results $(p=0.003$ or $<0.05)$. The family is expected to provide support in the form of motivation, support, and guidance in the form of moral and material so that patients are better able to follow the diabetes mellitus diet in maintaining blood sugar levels.

Keywords: Family Support, Diet Compliance, Diabetes Melitus. 


\section{PENDAHULUAN}

Diabetes Melitus merupakan penyakit kronis serius yang dimana pancreas tidak menghasilkan cukup insulin (hormon yang mengatur gula darah atau glukosa), atau ketika tubuh tidak dapat secara efektif menggunakan insulin yang dihasilkannya. Diabetes juga merupakan masalah kesehatan masyarakat yang penting, menjadi salah satu dari empat penyakit tidak menular prioritas yang menjadi target tindak lanjut oleh para pemimpin dunia. Jumlah kasus dan prevalensi diabetes terus meningkat selama beberapa dekade terakhir. (WHO Global Report, 2016). Diabetes menyebabkan 1,5 juta kematian pada tahun 2012. Gula darah yang lebih tinggi dari batas maksimum mengakibatkan tambahan 2,2 juta kematian, dengan meningkatkan risiko penyakit kardiovaskular dan lainnya. Empat puluh tigapersen (43\%) dari 3,7 juta kematian ini terjadi sebelum usia 70 tahun. Persentase kematian yang disebabkan oleh diabetes yang terjadi sebelum usia 70 tahun lebih tinggi di negara-negara berpenghasilan rendah dan menengah daripada di negara-negara berpenghasilan tinggi. (WHO Global Report, 2016).

Meningkatnya prevalensi diabetes melitus di beberapa negara berkembang, akibat peningkatan kemakmuran dinegara bersangkutan, akhir-akhir ini banyak disoroti. Peningkatan pendapatan per kapita dan perubahan gaya hidup terutama di kota-kota besar, menyebabkan peningkatan prevalensi penyakit degeneratif, seperti penyakit jantung koroner (PJK), hipertensi, hiperlipidemia, diabetes dan lain-lain. Hasil data epidemiologi di negara berkembang memang masih belum banyak. Hal ini disebabkan penelitian epidemiologik sangat mahal biayanya. Oleh karena itu prevalensi yang dapat ditelusuri terutama berasal dari negara maju (Suyono, 2018). Di Indonesia sendiri, berdasarkan data terbaru Riset Kesehatan Dasar 2018, secara umum angka prevalensi diabetes mengalami peningkatan cukup signifikan selama lima tahun terakhir. Di tahun 2013, angka prevalensi diabetes pada orang dewasa mencapai $6,9 \%$, dan di tahun 2018 angka terus melonjak menjadi 8,5\%. Sedangkan untuk provinsi Sumatera Utara prevalensi penderita diabetes mellitus sebanyak $1,8 \%$ atau sekitar 160 ribu jiwa.
Kepatuhan diet DM dipengaruhi oleh dua faktor yaitu faktor internal dan faktor eksternal. Faktor internal dalam kepatuhan diet DM adalah pendidikan, pengetahuan, keyakinan dan sifat kepribadian. Faktor eksternal adalah antara lain interaksi profesional kesehatan dengan pasien, faktor lingkungan dan faktor dukungan keluarga. Dukungan keluarga sangat penting dalam membantu pendidikan pasien DM dalam mematuhi diet. Ketika salah satu anggota keluarga mengalami masalah kesehatan, maka anggota keluarga yang lain sangat penting memberikan dukungannya, terutama dalam mematuhi diet DM (Rafani \& Ben, 2012).

Dampak positif dari dukungan keluarga dalam menjalankan diet pada penderita DM yaitu dapat mengontrol semua yang disarankan oleh tim kesehatan dalam menjalankan dietnya, dengan saling mengingatkan antara anggota keluarga terutama anggota keluarga yang sedang menjalankan diet sehingga penderita DM terdorong untuk tetap menjalankan diet dan berkeinginan terus untuk mempertahankan atau memperbaiki kualitas hidupnya (Soegondo, 2018).

Berdasarkan data dari Puskesmas Binjai Estate, hasil survey yang dilakukan peneliti di Puskesmas Binjai Estate dari 8 orang penderita DM, 3 orang mengatakan tidak didampingi oleh keluarga pergi ke puskesmas, 2 orang mengatakan keluarga kurang memperhatikan tentang penyakit pasien, dan 3 orang lainnya mengatakan mendapat dukungan keluarga seperti diantar ke puskesmas. Dari data tersebut ternyata masih ada penderita DM yang tidak didukung oleh keluarga atas penyakit yang diderita. Tujuan penelitian ini untuk mengetahui hubungan dukungan keluarga dengan kepatuhan menjalani diet pada pasien diabetes melitus.

\section{METODE}

Jenis penelitian ini menggunakan pendekatan analitik kuantitatif dengan desain studi korelasi deskriptif, untuk mengetahui hubungan dukungan keluarga dengan kepatuhan menjalani diet pada pasien diabetes melitus di wilayah kerja Puskesmas Binjai Estate tahun 2020. Populasi dalam penelitian ini merupakan seluruh penderita DM di wilayah kerja Puskesmas Binjai Estate 
sebanyak 125 orang. Sampel dalam penelitian ini adalah yang mewakili jumlah populasi yaitu dengan menggunakan rumus Arikunto yaitu mengambil sampel $20 \%$ dari jumlah populasi yaitu sebanyak 25 responden (Arikunto, 2010).

Analisa data dalam penelitian ini yaitu analisis univariat dan bivariat. Analisa univariat menggambarkan distribusi frekuensi dukungan keluarga dan kepatuhan diet yang dihitung dalam frekuensi dan persentase. Dukungan keluarga dikategorikan dengan 3 kategori yaitu: baik jika responden menjawab kuisioner 11-15 pertanyaan (73-100\%), cukup jika responden bisa menjawab 6-10 pertanyaan (40-67\%) dan dukungan kurang jika responden bisa menjawab pertanyaan 0-5 pertanyaan $(<40 \%)$. Kepatuhan diet dapat di hitung berdasarkan 2 kategori yaitu patuh apabila responden bisa menjawab 8-5 pertanyaan (53-100\%), kategori tidak patuh jika respondedn menjawab pertanyaan 0-7 pertanyaan $(<53 \%)$. Analisis bivariat dilakukan untuk menguji ada tidaknya hubungan dukungan keluarga dengan kepatuhan menjalankan diet pasien diabetes melitus di wilayah kerja Puskesmas Binjai Estate. Pengukuran dilakukan dengan pemberian kuisioner yang dikutip dari (Sulanjari, 2018) dan dimodifikasi oleh peneliti (tentang dukungan keluarga dengan kuisioner kepatuhan menjalankan diet. Uji statisti yang digunakan yaitu uji chi square yang dinyatakan bermakna apabila nilai $\mathrm{p}$ value $<0,05$ pada tingkat kepercayaan $95 \%$.

\section{HASIL DAN PEMBAHASAN}

\subsection{Hasil}

Univariat

Tabel 1. Distribusi Frekuensi Karakteristik Responden di Wilayah Kerja Puskesmas Binjai

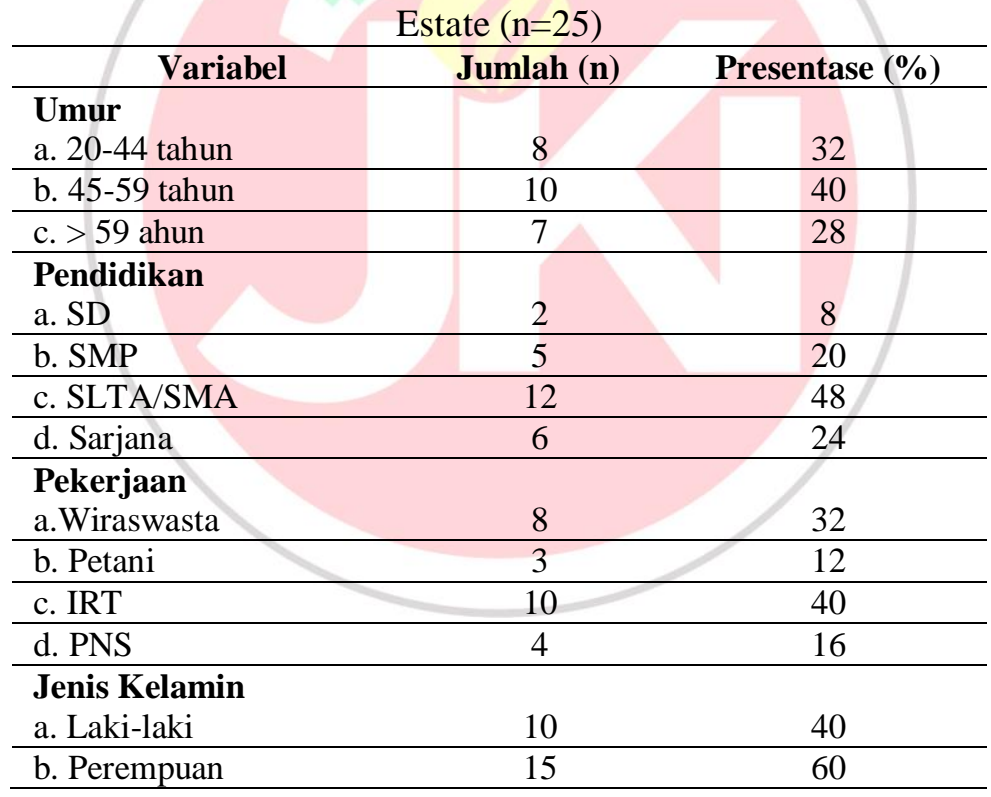

Pada tabel 1 dilihat frekuensi karakteristik responden berdasarkan umur mayoritas umur 45-59 tahun dengan jumlah 10 responden (40\%), berdasarkan pendidikan mayoritas SLTA/SMA sebanyak 12 responden $(48 \%)$, berdasarkan pekerjaan mayoritas IRT sebanyak 10 responden (40\%) dan berdasarkan jenis kelamin mayoritas perempuan sebanyak 15 responden $(60 \%)$.
Tabel 2. Distribusi Frekuensi Dukungan Keluarga Responden di Wilayah Kerja Puskesmas Binjai Estate Tahun $2020(\mathrm{n}=25)$

\begin{tabular}{|c|c|c|}
\hline Variabel & Jumlah (n) & Presentase $(\%)$ \\
\hline Dukungan & \multirow{3}{*}{13} & \multirow{3}{*}{52} \\
\hline Keluarga & & \\
\hline a. Baik & & \\
\hline b. Cukup & 9 & 36 \\
\hline c. Kurang & 3 & 12 \\
\hline
\end{tabular}

Pada tabel 2 dilihat berdasarkan variable frekuensi dukungan keluarga mayoritas baik sebanyak 13 responden $(52 \%)$. 
Tabel 3. Distribusi Frekuensi Kepatuhan

Menjalani Diet Responden Di Wilayah Kerja

Puskesmas Binjai Estate Tahun $2020(\mathrm{n}=25)$

\begin{tabular}{lcc}
\multicolumn{1}{c}{ Variabel } & Jumlah (n) & Presentase (\%) \\
\hline $\begin{array}{l}\text { Kepatuhan } \\
\text { Menjalani Diet }\end{array}$ & & \\
a. Patuh & 16 & 64 \\
\hline b. Tidak Patuh & 9 & 36 \\
\hline
\end{tabular}

Pada tabel 3 dilihat berdasarkan variabel kepatuhan menjalankan diet mayoritas responden patuh sebanyak 16 responden $(64 \%)$.

Tabel 4. Hubungan Dukungan Keluarga Dengan Kepatuhan Menjalani Diet Responden Di Wilayah Kerja Puskesmas Binjai Estate tahun $2020(n=25)$

\begin{tabular}{cccccccc}
\hline \multirow{2}{*}{$\begin{array}{c}\text { Dukungan } \\
\text { Keluarga }\end{array}$} & \multicolumn{3}{c}{ Kepatuhan Menjalani Diet } & \multicolumn{2}{c}{ Total } & \multirow{2}{*}{ P } \\
\cline { 2 - 6 } & \multicolumn{2}{c}{ Patuh } & \multicolumn{2}{c}{ Tidak Patuh } & & \\
\cline { 2 - 6 } & $\mathbf{N}$ & $\mathbf{\%}$ & $\mathbf{N}$ & $\mathbf{\%}$ & $\mathbf{N}$ & $\mathbf{\%}$ & \\
\hline Baik & 12 & 48 & 1 & 4 & 13 & 52 \\
\hline Cukup & 4 & 16 & 5 & 32 & 9 & 36 \\
\hline Kurang & 0 & 0 & 3 & 8 & 3 & 12 \\
\hline Total & $\mathbf{1 6}$ & $\mathbf{6 4}$ & $\mathbf{9}$ & $\mathbf{3 6}$ & $\mathbf{2 5}$ & $\mathbf{1 0 0}$ & \\
\hline
\end{tabular}

Pada tabel 4 di atas didapatkan responden yang memiliki dukungan keluarga baik, patuh dalam menjalankan diet DM sebanyak 12 responden (48\%), sedangkan dukungan keluarga kurang, tidak patuh dalam menjalani diet DM sebanyak 3 responden $(8 \%)$. Berdasarkan hasil uji statistik didapatkan $\mathrm{p}=0,003(\mathrm{p}<0,05)$ berarti $\mathrm{H}_{\mathrm{o}}$ ditolak, maka terdapat hubungan antara dukungan keluarga dengan kepatuhan menjalani diet pada penderita diabetes melitus di wilayah kerja Puskesmas Binjai Estate tahun 2020.

\subsection{Pembahasan \\ Dukunga Keluarga}

Berdasarkan hasil frekuensi dukungan keluara menunjukkan bahwa mayoritas responden memiliki dukungan keluarga baik yaitu 52 responden (52\%), hal ini disebabkan karena dukungan keluarga merupakan dua atau lebih dari individu yang tergabung karena hubungan darah, hubungan perkawinan yang hidup dalam suatu rumah tangga, berinteraksi satu sama lain dan dalam perannya masing-masing menciptakan serta mempertahankan kebudayaan, sesuai dengan fungsi pemeliharaan kesehatan, keluarga mempunyai tugas dibidang kesehatan yang perlu dipahami dan dilakukan (Chayatin, 2009).

Penelitian ini di dukung oleh penelitian yang dilakukan oleh (Sulanjari, 2018), dengan judul hubungan dukungan keluarga dengan kepatuhan menjalankan diet diabetes melitus di Poliklinik penyakit dalam RSUD dr. Sayidiman Magetan, menunjukkan bahwa sebagian besar terdapat 18 responden $(51,43 \%)$ mendapatkan dukungan keluarga yang baik dari total sampel 35 responden. Berdasarkan penelitian tersebut dukungan keluarga selalu diharapkan agar kondisi pasien semakin membaik karena dengan adanya dukungan keluaga pasien cenderung patuh akan menjalankan dietnya. Keluarga sangat diharapkan untuk memotivasi pasien agar dapat meningkatkan kepatuahn menjalani dietnya sesuai dengan saran petugas kesehatan.

Penelitian ini juga di dukung penelitian (Bangun et al., 2020) dengan judul hubungan dukungan keluarga denga kepatuhan diet pada penderita diabetes melitus type 2 , menunjukkan hasil dari 60 responden 56,3\% dukungan keluarga yang baik. Responden cemas jika tidak mematuhi diet akan meperburuk komplikasi dari DM, salah satu responden juga mengatakan selalu diawasi oleh anaknya dalam menkonsumsi diet sehari-hari sesuai dengan yang disarankan oleh petugas kesehatan.

Pasien memerlukan dukungan untuk patuh terhadap diet yang harus dijalani, pasien akan merasakan kualitas kesehatan maupun kualitas hidup yang meningkat pada saat patuh pada diet. Apabila makan dan minum dijaga akan terhindar dari berbagai macam komplikasi yang hanya akan memperparah dan memperburuk keadaan pasien serta meminimalisir adanya gangguan kesehatan lainnya. 


\section{Kepatuhan Menjalani Diet}

Berdasarkan hasil penelitian kepatuhan diet diketahui dari 25 responden di dapatkan hasil mayoritas yaitu 16 responden (64\%) penderita diabetes melitus memiliki kepatuhan diet dengan kategori patuh. Hal ini disebabkan karena kepatuhan diet merupakan kebutuhan untuk menjaga agarkadar gula darah seimbang dan tidak memperburuk kondisi tubuh, sesuai dengan hasil penelitian yang dilakukan oleh (Sulanjari, 2017) menunjukkan hasil 25 responden $(71,43 \%)$ patuh menjalani diet DM dari 35 jumlah total seluruh responden. Berdasarkan (Kemenkes, 2011) kepatuhan adalah suatu bentuk perilaku yang timbul karena adanya interaksi antara petugas kesehatan dengan pasien sehingga pasien mengetahui rencana dengan segala konsekuensinya sehingga menyetujui rencana tersebut serta melaksanakannya. Hal ini juga disebabkan karena kedua responden tersebut telah lama menderita DM yang rata-rata 6 tahun sehingga dapat mempengaruhi perilaku pasien dalam menjalani diet.

\section{Hubungan Dukungan Keluarga dengan Kepatuhan Menjalani Diet pada Pasien Diabetes Melitus}

Berdasarkan hasil penelitian menunjukkan bahwa hasil p-value $0,003<0,05$ artinya ada hubungan antara dukungan keluarga dengan kepatuhan menjalani diet pada pasien diabetes melitus di Puskesmas Binjai Estate Kota Binjai. Sesuai dengan penelitian (Sulanjari, 2017), tentang hubungan dukungan keluarga dengan kepatuhan menjalankan diet Diabtes Melitus di Poliklinik Penyakit Dalam RSUD DR Sayidiman Magetan menunjukkan bahwa analisa dengan uji rank spearmen diperoleh nilai $p$ value sebesar 0,002 sehingga $p$ value $<0.05$ dengan makna ada hubungan dukungan keluarga dengan kepatuhan menjalankan diet diabetes melitus dipoliklinik penyakit dalam RSUD dr Sayidiman Magetan. Berdasarkan penelitian tersebut dukungan keluarga selalu diharapkan agar kondisi pasien semakin membaik karena dengan adanya dukungan keluaga pasien cenderung patuh akan menjalankan dietnya. Keluarga sangat diharapkan untuk memotivasi pasienagar dapat meningkatkan kepatuhan menjalani dietnya sesuai dengan saran petugas kesehatan.

\section{KESIMPULAN}

Berdasarkan hasil uji chi square menunjukkan hasil terdapat hubungan dukungan keluarga dengan kepatuhan menjalankan diet pada pasien diabetes melitus di Puskesmas Binjai Estate. Disarankan kepada keluarga untuk memberikan support, yang berupa motivasi, dukungan dan bimbingan baik berupa moril dan material agar pasien lebih patuh menjalani diet diabetes mellitus dalam menjaga kadar gula darah. Bagi peneliti selanjutnya agar bisa meneliti dengan kasus ini karena dukungan keluarga yang optimal akan memberikan hasil yang positif bagi penderita diabetes mellitus dalam menjalankan dietnya sehingga mengurangi masalah yang timbul dalam penderita diabetes melitus.

\section{REFERENCES}

ADA, A. D. (2014). Diagnosisand Clasification of Diabetes Mellitus. Diabetes Care. Jan: 34 (Supp l1), S62S69.

American, D. A. (2012). Diabetes Care The Journal of Clinical and Applied Research and Education. Volume 42, Supplement 1, 54.

Arikunto, S. (2010). Prosedur Penelitian Suatu Pendekatan Praktek. Yogyakarta: Rineka Cipta.

Bangun, A. V., Jatnika, G., \& Herlina. (2020). Hubungan antara Dukungan Keluarga dengan Kepatuhan Dietpada Penderita Diabetes Mellitus Tipe 2. 3 (1), 66-76.

http://pustaka.unpad.ac.id/wpcontent/uploads/2015/01/ArtikelIlmiah1.pdf

Damayanti, D. (2013). Sembuh Total Diabetes, Asam Urat, Hipertensi Tanpa Obat. Yogyakarta: Pinang Merah.

Damayanti, S. (2018). Diabetes Mellitus \& Penatalaksanaan Yogyakarta: Nuha Medika.

Friedman M and Marilyn. 2010. Buku Ajar Keperawatan Keluarga: Riset, Teori \& Praktek. Jakarta: EGC. hlm. 108-225.

Hidayat, A. A. (2007). Metode Penelitian Keperawatan dan Teknik Analisis Data. Jakarta: Salemba Medika.

Nursalam. (2008). Konsep dan Penerapan Metodologi Penelitian Ilmu Keperawatan. Jakarta: Salemba Medika. 
PERKENI. (2011). Konsensus pengelolaan Sulanjari, E. (2018). Hubungan Dukungan

diabetes melitustipe 2 di indonesia 2011. Semarang: PBPERKENI.

Prof. DR. Dr. Sidartawan Soegondo, S.-P.-K. F. (2018). Penatalaksanaan Diabetes Melitus Terpadu, Edisi kedua. Jakarta: Balai Penerbit FKUI.
Keluarga Dengan Kepatuhan Menjalankan Diit Diabetes Mellitus Di Poliklinik Penyakit Dalam RSUD Dr. Sayidiman Magetan. Journal of Chemical Information and Modeling, 53 (9), 1689-1699.

https://doi.org/10.1017/CBO978110741 5324.004.

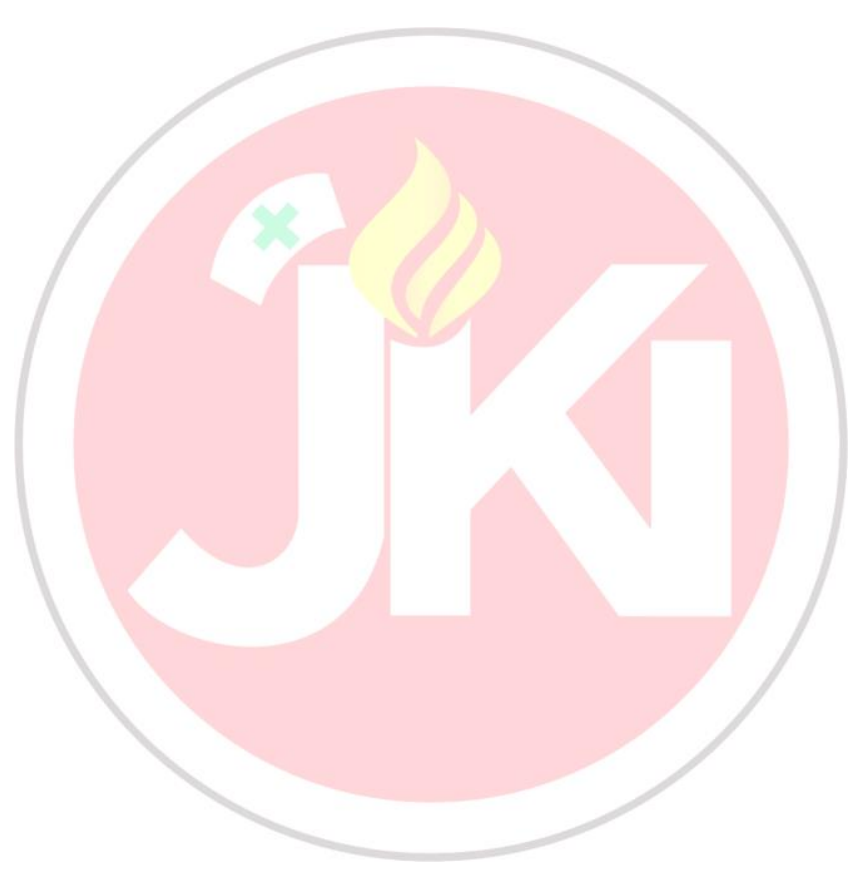

